\title{
Letramentos acadêmicos em PLE: escrevendo a sociedade e a cultura brasileira na Coreia do Sul
}

\author{
Denis Leandro Francisco ${ }^{1}$ \\ Hankuk University of Foreign Studies, College of International and Area Studies, Department of Brazilian \\ Studies, Yongin-si, South Korea
}

Resumo: Este artigo apresenta uma prática de escrita realizada com estudantes de Estudos Brasileiros no contexto do ensino superior sul-coreano. Partindo-se do modelo ideológico de letramento (STREET, 1995), empregou-se o gênero portfólio como dispositivo didático com o objetivo principal de desenvolver a autonomia dos estudantes e o seu posicionamento crítico em relação aos tópicos socioculturais tratados durante o semestre letivo. A organização das etapas que envolveram essa prática, bem como as produções textuais dela resultantes, indicam, em relação ao grupo de estudantes coreanos que dela participaram, i. uma baixa familiaridade com práticas pedagógicas voltadas para o letramento acadêmico de modelo ideológico, sejam essas práticas em LE ou em LM; ii. a capacidade de se engajar na prática de escrita proposta, a despeito do pouco contato prévio com o gênero portfólio, produzindo textos críticos que configuram autoria; e iii. a avaliação desse tipo de prática pedagógica como importante para a aprendizagem da língua-cultura alvo, além de mais relevante do que práticas tradicionais não voltadas para o letramento de modelo ideológico.

Palavras-chave: Letramentos acadêmicos em PLE; Portfólio; Ensino superior; Estudos Brasileiros; Coreia do Sul.

Title: Academic literacies in PFL: writing Brazilian society and culture from South Korea

Abstract: This article presents a writing practice conducted with students of Brazilian Studies in the context of South Korea higher education. Based on the ideological model of literacy (STREET, 1995), we proposed the genre portfolio as a pedagogical tool with the main goal of developing the students' autonomy and their critical thinking towards the socio-cultural topics approached during the course. The preparation of the stages that involved this practice, as well as the textual productions resulted, indicate that, concerning to the group of Korean students who took part in it: i. the students have little familiarity with pedagogical practices geared towards academic literacy, whether in mother tongue or foreign language; ii. despite the lack of prior contact with the portfolio genre, the students were able to produce texts strongly critical and authorial by engaging themselves in the writing practice proposed; and iii. the students consider this kind of pedagogical practice important for the learning of a target language/target-culture also more relevant than traditional practices not focused on academic literacy.

Keywords: Academic literacies in PFL; Portfolio; Higher education; Brazilian Studies; South Korea.

1 Doutor em Literatura Comparada (UFMG), Hankuk University of Foreign Studies. Orcid: https://orcid.org/0000-0001-5947-8832

E-mail: denisleandro@outlook.com 


\section{Sistema educacional sul-coreano: breve (e necessária) contextualização}

A Coreia do Sul é, já há algumas décadas, internacionalmente conhecida pela sua música nacional (o $K$-pop) e pela elevada qualidade do seu sistema educacional. Na última edição do Programme for International Student Assessment (PISA), em 2015, os estudantes coreanos apresentaram desempenho superior a países como Reino Unido, Alemanha e Suíça, ocupando a 11 á posição dentre os países da Organização para a Cooperação e o Desenvolvimento Econômico (OCDE), conforme mostra a Tabela 1 a seguir:

Tabela 1 - PISA 2015: Snapshot of performance in science, reading and mathematics

\begin{tabular}{|c|c|c|c|c|c|c|c|c|}
\hline & \multicolumn{2}{|c|}{ Science } & \multicolumn{2}{|c|}{ Reading } & \multicolumn{2}{|c|}{ Mathematics } & \multicolumn{2}{|c|}{ Science, reading and mathematics } \\
\hline & $\begin{array}{l}\text { Mean scoore } \\
\text { in PISA 2015 }\end{array}$ & $\begin{array}{c}\text { Average } \\
\text { three-year trend }\end{array}$ & $\begin{array}{l}\text { Mean score } \\
\text { in PISA } 2015\end{array}$ & $\begin{array}{l}\text { Average three- } \\
\text { year trend }\end{array}$ & $\begin{array}{l}\text { Mean score } \\
\text { in PISA 2015 }\end{array}$ & $\begin{array}{c}\text { Average } \\
\text { three-year trend }\end{array}$ & $\begin{array}{l}\text { Share of top performers in at } \\
\text { least one subject (Level } 5 \text { or } 6 \text { ) }\end{array}$ & $\begin{array}{l}\text { Share of low achievers in all } \\
\text { three subjects (below Level 2) }\end{array}$ \\
\hline & Mean & Soore dif. & Mean & Score dif. & Mean & Score dif. & $\%$ & $\%$ \\
\hline $\mathrm{OECD}$ average & 498 & -1 & 493 & -1 & 490 & -1 & 15.3 & 13.0 \\
\hline Singapore & 556 & 7 & 535 & 5 & 564 & 1 & 39.1 & 4.8 \\
\hline dapan & 538 & 3 & 516 & -2 & 532 & 1 & 25.8 & 5.6 \\
\hline Estonia & 534 & 2 & 519 & 9 & 520 & 2 & 20.4 & 4.7 \\
\hline Chinese Taipei & 532 & 0 & 497 & 1 & 542 & 0 & 29.9 & 8.3 \\
\hline Finland & 531 & -11 & 526 & -5 & 511 & -10 & 21.4 & 6.3 \\
\hline Macas (China) & 529 & 6 & 509 & 11 & 544 & 5 & 23.9 & 3.5 \\
\hline Canada & 528 & -2 & 527 & 1 & 516 & -4 & 22.7 & 5.9 \\
\hline Viet Nam & 525 & -4 & 487 & -21 & 495 & -17 & 12.0 & 4.5 \\
\hline Hong Kong (China) & 523 & -5 & 527 & $\frac{-13}{3}$ & 548 & 1 & 29.3 & 4.5 \\
\hline B-S J-G (China) & 518 & $\mathrm{~m}$ & 494 & $\mathrm{~m}$ & 531 & $\mathrm{~m}$ & 27.7 & 10.9 \\
\hline Korea & 516 & -2 & 517 & -11 & 524 & 3 & 25.6 & 7.7 \\
\hline New Zealand & 513 & -7 & 509 & -6 & 495 & -8 & 20.5 & 10.6 \\
\hline Slovenia & 513 & -2 & 505 & 11 & 510 & 2 & 18.1 & 8.2 \\
\hline Australia & 510 & -6 & 503 & -6 & 494 & -8 & 18.4 & 11.1 \\
\hline United Kingdom & 500 & -1 & 498 & 2 & 492 & -1 & 16.9 & 10.1 \\
\hline Germany & 509 & -2 & 500 & 6 & 506 & 2 & 19.2 & 9.8 \\
\hline Netherlands & 509 & -5 & 503 & -3 & 512 & -6 & 20.0 & 10.9 \\
\hline Switzerland & 506 & -2 & 492 & -4 & 521 & -1 & 22.2 & 10.1 \\
\hline Ireland & 500 & 0 & 521 & 13 & 504 & 0 & 15.5 & 6.8 \\
\hline Belgium & 502 & -3 & 499 & -4 & 507 & -5 & 19.7 & 12.7 \\
\hline Dermark & 500 & 2 & 5000 & 3 & 511 & -2 & 14.9 & 7.5 \\
\hline Poland & 501 & 3 & 506 & 3 & 504 & 5 & 15.8 & 8.3 \\
\hline Portugal & 501 & 8 & 498 & 4 & 4902 & 7 & 15.6 & 10.7 \\
\hline Brazil & 401 & 3 & 407 & -2 & 377 & 6 & 2.2 & 44.1 \\
\hline $\begin{array}{l}\text { Dozin } \\
\text { Peru }\end{array}$ & 397 & 14 & 398 & 14 & 387 & 10 & 0.6 & 46.7 \\
\hline Lebanon & 386 & $\mathrm{~m}$ & 347 & $\mathrm{~m}$ & 396 & $\mathrm{~m}$ & 2.5 & 50.7 \\
\hline 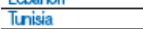 & 386 & 0 & 361 & -21 & 360 & $\frac{111}{4}$ & $\frac{.20}{0.6}$ & 57.3 \\
\hline FYAOM & 384 & $\mathrm{~m}$ & 352 & $\mathrm{~m}$ & 371 & $\mathrm{~m}$ & 1.0 & 52.2 \\
\hline Kosowo & 378 & $\mathrm{~m}$ & $\frac{02}{347}$ & $m$ & 362 & $\mathrm{~m}$ & 0.0 & $\frac{0.4}{60.4}$ \\
\hline Algeria & 376 & $\mathrm{~m}$ & 350 & $\mathrm{~m}$ & 360 & $\mathrm{~m}$ & 0.1 & 61.1 \\
\hline Dominican Republic & 332 & $\mathrm{~m}$ & 358 & $\mathrm{~m}$ & 328 & $\mathrm{~m}$ & 0.1 & 70.7 \\
\hline
\end{tabular}

Fonte: Disponível em: http://www.oecd.org/pisa/pisa-2015-results-in-focus.pdf.

Acesso em: 04 out. 2018.

O PISA mede o desempenho de "15-year-old students, near the end of their compulsory education", avaliando em que extensão esses estudantes "have acquired key knowledge and skills that are essential for full participation in modern societies" ${ }^{2}$. Ainda que os resultados do PISA não se refiram ao desempenho de estudantes universitários, é válido tê-los em perspectiva porque esses resultados indicam o background dos estudantes que, tendo concluído o bem avaliado ensino fundamental coreano, ingressarão posteriormente em uma das instituições de ensino superior do país, contexto em que foi realizada a prática pedagógica de letramento que este artigo apresenta.

\footnotetext{
2 PISA 2015: results in focus. Disponível em: http://www.oecd.org/pisa/pisa-2015-results-in-focus.pdf. Acesso em: 04 out. 2018.
} 
A Hankuk University of Foreign Studies (HUFS) é considerada a melhor instituição sulcoreana na área de Estudos Estrangeiros, sendo amplamente reconhecida pela sua posição de destaque em toda a Ásia, sobretudo em Ciências Sociais e Línguas Modernas. Atualmente a instituição, que conta com dois campi, oferta 45 idiomas em cursos de Graduação. Ao todo são 10 faculdades e 74 departamentos na universidade. Em 2016, a instituição foi avaliada como a 10a universidade mais respeitável da Coréia do Sul de acordo com uma pesquisa realizada pelo Joong-Ang Daily University Rankings ${ }^{3}$ nas 69 principais universidades do país. Em uma outra pesquisa compilada e divulgada em 2016 pelo Chosun Ilbo (periódico diário de maior circulação do país) e desenvolvida pela Quacquarelli Symonds - "QS" (companhia britânica especializada em educação e internacionalização), a HUFS aparece em primeiro lugar na lista de universidades sul-coreanas "sem faculdades de Medicina", figurando ainda entre as 10 mais renomadas universidades da Ásia. A pesquisa foi realizada em 517 universidades em 17 países e regiões asiáticas, incluindo, além da Coréia do Sul, Japão, China, Cingapura e Hong Kong, conforme mostra a Tabela 2 a seguir:

Tabela 2 - Posição da HUFS entre as universidades asiáticas sem Faculdade de Medicina

Comprehen sive, large universities with no medical school

\begin{tabular}{|c|l|l|}
\hline Ranking & \multicolumn{1}{|c|}{ University } & \multicolumn{1}{|c|}{ Country } \\
\hline 1 & The Hong Kong University of Science and Technol ogy & Hong Kong \\
\hline 2 & University of Science and Technology of China & China \\
\hline 3 & The Hong Kong Polytechnic University & Hong Kong \\
\hline 4 & Beijing Normal University & China \\
\hline 5 & Waseda University & Japan \\
\hline 6 & Universiti Teknologi Malaysia & Malaysia \\
\hline 7 & Shanghai University & China \\
\hline 8 & Tianjin University & China \\
\hline 9 & Hankuk University of For eign Studies(HUFS) & South Korea \\
\hline 10 & East China Normal University & China \\
\hline
\end{tabular}

Source : 2016 Chosun Ilbo-QS Asia University Rankings

Fonte: Disponível em: http://www.hufsnews.co.kr/news/articleView.html?idxno=13837. Acesso em: 07 out. 2017.

É esse o contexto acadêmico específico dos estudantes do curso de Graduação em Estudos Brasileiros que, no primeiro semestre de 2017 e no primeiro semestre de 2018, cursaram a disciplina Seminário sobre Sociedade e Cultura Brasileira I ${ }^{4}$. Ao todo, 20 estudantes

\footnotetext{
${ }^{3}$ Disponível em: http://www.hufsnews.co.kr/news/articleView.html?idxno=14074. Acesso em: 07 out. 2017.

${ }^{4}$ Seminário, deste ponto em diante.
} 
(10 a cada semestre), todos do $4^{\circ}$ ano, frequentaram a disciplina, que é ministrada em língua portuguesa.

Apesar da qualidade geral do sistema educacional sul-coreano, indicada por reconhecidos instrumentos de avaliação educacional como o PISA, e da classificação da Hankuk University no ranking das melhores instituições de ensino superior asiáticas, as práticas pedagógicas tradicionais ainda predominam sobre práticas mais atuais que visam ao desenvolvimento dos diferentes letramentos acadêmicos, seja no ensino de línguas estrangeiras ou de outras disciplinas que compõem o diversificado currículo dos Area Studies. Essa informação foi coletada informalmente pelo pesquisador a partir de consulta aos seus estudantes de graduação e a outros professores (tanto coreanos como estrangeiros) ao longo dos dois primeiros anos de trabalho na instituição.

O sistema educacional coreano, desde a educação básica até o ensino superior, baseiase em um modelo de ensino focado em conteúdos e ainda centrado no professor, com pouca ou nenhuma abertura para intervenção/participação ativa do estudante, modelo esse que não favorece o desenvolvimento da autonomia e do posicionamento crítico do estudante em relação aos conteúdos curriculares e ao seu próprio processo de aprendizagem. Seguindo esse mesmo modelo de ensino, os métodos de avaliação são também bastante tradicionais, dividindo-se, de modo geral, em provas institucionalmente instituídas (Midterm Exam e Final Exam são obrigatórios para todos os cursos em todos os departamentos), testes de verificação de informações apresentadas pelos livros didáticos e, menos frequentemente, apresentações de seminários. Nesses três casos, o professor avalia o produto da aprendizagem e não o processo, conferindo ao estudante uma nota numérica que é classificatória e, além disso, relativa: no sistema coreano, as notas dos demais estudantes são definidas em relação à maior nota obtida.

Pode-se inferir, pelo quadro aqui brevemente apresentado, que dos três modelos concebidos por Lea e Street (1998) para abordar escrita e letramento em contextos acadêmicos - habilidades acadêmicas (study skills), socialização acadêmica (academic socialization) e letramento acadêmico (academic literacy) -, o primeiro modelo (study skills), centrado em aspectos da superfície do texto, parece ocupar uma posição de centralidade no contexto universitário sul-coreano, contudo, como não dispomos de dados suficientes no momento para sustentar essa generalização, restringiremos nossas considerações e nossas conclusões ao espaço acadêmico em que foi realizada a prática pedagógica aqui posta em análise.

No momento da apresentação da nossa proposta de prática de escrita aos estudantes do Seminário, as reações dos estudantes foram de completo espanto e incredulidade diante da proposta pedagógica, com duas ocorrências de desistência formal da disciplina (o que, por outro lado, não é incomum no contexto sul-coreano, devido à citada nota relativa e ao peso do histórico acadêmico dos candidatos na disputa por uma vaga no mercado de trabalho). Mas, como é essa proposta pedagógica que deixou o nosso grupo de estudantes universitários 
sul-coreanos, em um primeiro momento, tão céticos acerca da sua própria capacidade de produzir, com autonomia, textos escritos que configurassem, de fato, autoria?

\section{Uma "velha nova novidade": o gênero portfólio em uma prática de letramento acadêmico em PLE}

Também em nosso contexto sul-coreano, os alunos enfrentam dificuldades quando precisam atender a demandas que envolvem a leitura e a escrita acadêmicas. Portanto, o letramento acadêmico - domínio que, ao longo das últimas décadas, assumiu crescente relevância no contexto brasileiro de ensino-aprendizagem (MOTTA-ROTH, 2009; MARINHO, 2010; FIAD 2011, 2013) - também precisa ser trazido para a sala de aula universitária coreana em forma de práticas que coloquem o estudante em contato com diferentes gêneros do domínio discursivo acadêmico a fim de desenvolver as habilidades que possibilitam ler e escrever textos desses gêneros de forma adequada e eficiente, nas diversas situações acadêmicas em que os estudantes se envolvem, em interação com diferentes interlocutores e para atender a diferentes objetivos. Constatada essa necessidade, elegeu-se o gênero portfólio para a prática pedagógica apresentada neste artigo por se apostar, principalmente, no seu elevado potencial para engajar os estudantes em um prática de letramento escrito particularmente favorável ao desenvolvimento da autonomia, do pensamento crítico e da autoria na produção textual.

O gênero portfólio como dispositivo didático, no entanto, não é exatamente novo: o portfólio vem sendo empregado tanto como estratégia de ensino-aprendizagem quanto como instrumento de avaliação há pelo menos vinte anos em universidades americanas (SELDIN, 2004) e, de lá para cá, o portfólio alcançou diversas universidades em outros continentes em um sem-número de variações e com diferentes aplicações. Porém, se é verdade que no contexto educacional brasileiro, de modo geral, o gênero portfólio como dispositivo didático ou como instrumento avaliativo não é mais uma novidade assim tão nova, no contexto universitário sul-coreano de realização da nossa prática de escrita esse gênero não faz parte da realidade acadêmica de estudantes e professores. Nenhum dos 20 estudantes matriculados nas duas edições do Seminário havia tido contato prévio com esse gênero, fosse ele empregado como recurso didático ou como instrumento de avaliação.

Essa constatação parece coadunar-se com as informações fornecidas tanto pelos estudantes quanto por professores sobre a predominância de práticas pedagógicas tradicionais envolvendo leitura e escrita no contexto acadêmico de realização da prática. Nesse espaço acadêmico, conforme dissemos, prevalece o modelo study skills (LEA; STREET, 1998), o qual centra-se nos aspectos formais da linguagem, tendo como pressuposto que o domínio de normas gramaticais e regras sintáticas garante o desempenho do estudante em relação à escrita acadêmica, subestimando a intrínseca relação entre escrita, construção de saberes disciplinares (LEA; STREET, 1998) e adequação à situação comunicativa por meio da 
mobilização de diferentes tipos de conhecimentos - linguísticos e enciclopédicos, mas também textuais e interacionais (KOCH; ELIAS, 2006, 2009) - e de diferentes estratégias de construção textual. Essa sobrevalorização dos aspectos formais em detrimento de outros igualmente importantes, como os sociointeracionais e culturais, alinha-se aos resultados apontados por outra pesquisa desenvolvida nesse mesmo contexto acadêmico (FRANCISCO, 2018) e que indicaram uma forte demanda, por parte dos estudantes universitários, por aulas cuja abordagem se aproximasse de uma perspectiva comunicativa ao invés de se manterem atreladas a um modelo tradicional de ensino-aprendizagem de língua estrangeira, centrado no professor e devotado a "transmitir" conhecimentos gramaticais e enciclopédicos.

A baixa familiaridade dos estudantes com o gênero textual em questão não foi, entretanto, tomada como legitimação para queixas da parte do professor de que os estudantes chegam ao ensino superior mal preparados para o que essa formação acadêmica altamente especializada espera deles, queixas que pesquisas têm mostrado serem frequentes no contexto acadêmico brasileiro (HENDERSON; HIRST, 2006). Conforme se viu na breve contextualização do sistema educacional coreano, a considerarmos os resultados de exames internacionais que aferem a qualidade do sistema educacional, os estudantes coreanos apresentam excelente desempenho ao final do ensino fundamental. Na nossa proposta didática de letramento, procurou-se evitar uma visão de "letramento acadêmico [que] é construído no interior de discursos de déficit e remediação" (HENDERSON; HIRST, 2006, p. 26) por considerarmos que esse discurso em nada favorece o processo de ensino-aprendizagem e, além disso, no caso específico da Coreia do Sul, carece de maiores investigações para se verificar em que medida o ensino pré-universitário ${ }^{5}$ sul-coreano tem ou não favorecido a participação dos estudantes em práticas de letramento.

Esse discurso do déficit subjaz a um modelo de letramento em contexto acadêmico definido por Street (1984) como modelo autônomo: nesse modelo, o letramento é considerado como um conjunto universal e imutável de habilidades técnicas, estados ou eventos cognitivos que, sendo universais, não levam em consideração aspectos sociais e culturais, por exemplo. Em oposição a essa concepção de letramento acadêmico, Street (1995, 2003) conceituou um outro modelo, o modelo ideológico de letramento:

O modelo ideológico alternativo de letramento oferece uma visão com maior sensibilidade cultural das práticas de letramento, na medida que elas variam de um contexto para o outro. Esse modelo parte de premissas diferentes das adotadas pelo modelo autônomo - propondo por outro lado que o letramento é uma prática de cunho social, e não meramente uma habilidade técnica e neutra, e que aparece sempre envolto em princípios epistemológicos socialmente construídos (STREET, 2003, p. 4-5).

\footnotetext{
${ }^{5} \mathrm{O}$ sistema educacional sul-coreano está organizado da seguinte forma: Elementary School (7 a 12 anos), Middle School (13 a 15 anos), High School (16 a 18 anos) e College.
} 
Vê-se que, da perspectiva do modelo ideológico de letramento, portanto, não há por que tratar as dificuldades como déficit, uma vez que as práticas de letramento são práticas socioculturais crivadas por relações de poder e, como tais, algumas dessas práticas podem estar acessíveis a alguns grupos e não a outros. Além disso, o modelo ideológico de letramento mostra-se ainda mais adequado à nossa prática de escrita no contexto universitário sulcoreano porque nos adverte sobre o aspecto cultural das práticas de letramento, orientandonos para a necessária sensibilidade cultural em relação a essas práticas, a fim de evitarmos projetar sobre elas as nossas próprias expectativas e os nossos próprios preconceitos forjados pelo nosso contexto cultural de origem, diverso daquele dos estudantes.

A nossa prática de escrita partiu, então, do modelo ideológico de letramento para propor aos estudantes a confeç̧ão de um portfólio sobre diversos tópicos relacionados à sociedade e à cultura brasileira abordados no Seminário. Considerando que o contexto acadêmico sul-coreano apresenta relações de poder muito mais rígidas que as verificadas no contexto acadêmico e na sociedade brasileira como um todo, e que essas relações se desenvolvem em práticas discursivas também diversas, com formas, em geral, mais conservadoras de tratar os textos e os gêneros textuais, a nossa proposta de prática de escrita visou possibilitar aos estudantes a autonomia necessária para entrarem em contato com o gênero portfólio e refletirem sobre como eles poderiam acessar e manipular esse gênero de forma a melhor atender aos seus projetos de texto.

Assim, o uso do gênero portfólio foi desenvolvido através das lentes do modelo ideológico de letramento na medida em que oportunizou, nos diferentes momentos de sua produção, a reflexão sobre as diversas relações de poder que envolvem as práticas letradas, em especial no ambiente acadêmico, e sobre as expectativas culturais relacionadas a essas práticas, buscando-se retirar o foco do modelo de study skills e abrindo espaço para usos efetivos do letramento, em sua complexidade, dinamicidade e situacionalidade social. Nesse sentido, a prática de escrita englobou dois momentos: um momento coletivo (para a realização de anotações iniciais em sala de aula, a partir da intervenção do professor e da colaboração dos colegas, com discussões e a socialização dos pontos de vista de cada um sobre o tema em questão) e um momento individual (em que o estudante deveria refletir sobre o que foi compartilhado e debatido no espaço acadêmico, reelaborar suas anotações de aula e desenvolver a redação final do seu portfólio).

$\mathrm{Na}$ primeira aula, os estudantes receberam, por escrito, as orientações sobre a proposta e foi aberto espaço para a apresentação e a discussão do conceito de portfólio. Também nesse momento inicial, foram apresentados exemplos de textos desse gênero para que os estudantes pudessem visualizar a diversidade de portfólios possíveis de serem produzidos e, ao mesmo tempo, travarem contato com as possibilidades estruturais do gênero, que, conforme afirma Bakhtin, são "enunciados estilísticos, temáticos e composicionais relativamente estáveis" (2011, p. 266) e não fôrmas engessadoras da capacidade criativa do enunciador. O Quadro 1 apresenta o material orientativo sobre portfólio: 
Quadro 1 - Material orientativo sobre portfólio

\section{PORTFÓLIO ACADÊMICO}

\section{O que é um portfólio acadêmico?}

Portfólio acadêmico é um conjunto organizado dos trabalhos produzidos pelo aluno (e do seu percurso individual de produção) ao longo de determinado período (o semestre acadêmico, por exemplo). Quando bem realizada, essa coletânea pessoal se transforma em um excelente instrumento de aprendizagem.

\section{O portfólio permite fazer, pensar sobre o que se fez e refazer.}

\section{0 portfólio é um resumo da aula?}

Não. O portfólio é uma apresentação pessoal do que você fez (e como) e do que você aprendeu (e como) em cada aula. Ele deve mostrar o seu processo de aprendizagem (realizações e dificuldades), além de apresentar os produtos dessa aprendizagem.

Instituto Antônio Houaiss

Dicionário eletrônico Houaiss da língua portuguesa 3.0

\section{portfólio Datação: sxx}

- substantivo masculino

1 cartão duplo desdobrável, us. para guardar papéis; pasta, porta-fólio

2 conjunto ou coleção do que está ou pode ser guardado num portfólio

3 Rubrica: publicidade.

conjunto de trabalhos de um artista, ou de fotos de ator ou modelo, ou de anúncios de uma agência us. para divulgação; buque

4 Rubrica: economia.

ver CARTEIRA ('conjunto de titulos')

Etimologia

ing. portfolio 'pasta para carregar papéis'

\section{Quais as partes de um portfólio?}

A estrutura de um portfólio pode (e deve) variar de acordo com os seus objetivos. O portfólio no nosso curso Seminário sobre sociedade e cultura brasileira deve ter, pelo menos, as seguintes partes:

Introdução: o que eu quero mostrar com esse portfólio? (objetivo)

Apresentação pessoal da aprendizagem realizada no dia (com data): apresentação + reflexão diária $\rightarrow 14$ encontros/aulas

Conclusão: reflexão posterior sobre o trabalho realizado no semestre acadêmico. 
O material orientativo sobre portfólio foi, conforme dissemos, discutido com os estudantes. Esse material, como se pode notar, traz a especificação "acadêmico" para qualificar e delimitar um pouco mais o gênero portfólio que, tal como descrito nas próprias orientações, é bastante flexível tanto em relação à sua estrutura quando à sua função. Como ressalta Marcuschi (2010, p. 20), os gêneros textuais "surgem, situam-se e integram-se funcionalmente nas culturas em que se desenvolvem", sendo, portanto, formas de ação social, práticas de produção de sentidos através da linguagem, delineadas social e historicamente, as quais "caracterizam-se muito mais por suas funções comunicativas, cognitivas e institucionais do que por suas peculiaridades linguísticas e estruturais". Isso não significa, como o próprio autor ressalta, que as propriedades formais que caracterizam os gêneros possam ser desconsideradas, mas mostra que essas formas são apenas "relativamente estáveis", conforme destacou Bakhtin (2011).

Portanto, o gênero portfólio adquire, na nossa proposta de letramento acadêmico, uma configuração própria para atender a um propósito específico: materializar, em uma prática de escrita em português como língua estrangeira (PLE), a reflexão dos estudantes sobre a sua própria aprendizagem de conceitos, contextos e aspectos da sociedade e da cultura brasileira, funcionando, ao mesmo tempo, como dispositivo didático e como instrumento avaliativo do processo de aprendizagem. Nesse sentido, o portfólio acadêmico proposto em nossa prática pode ser considerado um "portfólio de aprendizagem":

\begin{abstract}
Tradicionalmente ligado ao mundo das artes visuais e da moda, o conceito de portfólio quebrou fronteiras e adquiriu uma reconfiguração específica no campo educativo. Portfólio de Aprendizagem pode ser uma ferramenta pedagógica que permite a utilização de uma metodologia diferenciada e diversificada de monitoramento e avaliação do processo de ensino e aprendizagem [...]. O uso de portfólios de aprendizagem dá relevância e visibilidade ao processo formativo de aquisição e desenvolvimento de competências. O seu caráter compreensivo, de registro longitudinal, permite verificar dificuldades e agir em processo, no tempo da aprendizagem, ajudando ao estudante (AMBRÓSIO, 2013, p. 337).
\end{abstract}

O monitoramento da prática de escrita foi feito a partir de demanda: sempre que um estudante solicitava alguma orientação adicional sobre o portfólio, essa orientação era dada a todo o grupo, que participava, muitas vezes, trazendo novas dúvidas para a discussão. Exemplos de dúvidas trazidas pelos estudantes (algumas delas acompanhadas de demonstrações de elevada preocupação/insegurança) são: "Eu tenho que escrever uma folha de portfólio pra cada aula?"; "Tem um número mínimo de páginas?"; "Não vai ter uma pergunta pra gente responder?"; "No portfólio eu tenho que escrever tudo que você falou na aula?". Ainda que muitas das respostas a essas perguntas já estejam contempladas no material orientativo sobre portfólio entregue e discutido na primeira aula (Quadro 1), é natural e esperado que durante o processo de produção dos textos os estudantes, sentindose inseguros diante desse que para eles era um novo gênero textual, trouxessem para a sala de aula perguntas para as quais, muitas vezes, eles já sabiam a resposta, mas sentiam 
necessidade de receber uma confirmação do professor, uma "garantia" de que eles estavam "no caminho certo" da sua jornada textual.

Esta seção descreveu a nossa proposta de letramento acadêmico a partir do gênero textual portfólio. A seção a seguir discute diversos aspectos observados durante o processo de produção dos textos e destaca alguns resultados dessa prática de escrita realizada com estudantes universitários coreanos.

Escrevendo a sociedade e a cultura brasileira na Coreia do Sul: "Choquei. Choquei muito quando eu ouvi a música 'Carne' pela primeira vez"

A prática de escrita proposta apresentava dois macrodesafios ao estudante universitário coreano: i. familiarizar-se com um gênero textual específico e, até então, desconhecido dos estudantes (pelo menos do ponto de vista da sua produção, ainda que não necessariamente em relação ao reconhecimento e identificação de textos desse gênero, conforme demonstrou a etapa de visualização de portfólios buscados na Internet); ii. escrever, em língua estrangeira (PLE), sobre aquele que talvez seja "o mais estrangeiro dos países" para um coreano, o Brasil. Do lado de cá do globo, no Ásia, o Brasil é ainda muitas vezes visto como um país "exótico", "perigoso" e "desorganizado" ou, no outro extremo desse espectro, como uma "zona franca" de "alegrias", "afetividades" e "liberdades" plenas. Diante desses dois macrodesafios, por que, então, eleger o gênero portfólio para a escrita de temas complexos relacionados à sociedade e à cultura brasileira?

O gênero portfólio acadêmico foi selecionado pelo professor para que os estudantes pudessem se colocar em sua escrita sobre o Brasil e desenvolver sua autonomia. Ao contrário de outros gêneros acadêmicos, como o resumo e mesmo a resenha, o portfólio favorece a constituição e a expressão da autoria na prática de escrita, contribuindo para a superação daquilo que Marcuschi (1996) chamou de "exercícios de copiação": práticas de escrita de repetição e cópia de informações provenientes de textos lidos ou através de respostas a questionários previsíveis e pouco ou nada significativos.

É possível superar essa prática de produção de texto esvaziada de sentido através do gênero portfólio acadêmico porque o portfólio acadêmico não quer repetição, quer organização do pensamento e reelaboração da informação recebida; o portfólio acadêmico não quer cópia do material lido, quer reflexão sobre o que foi discutido; o portfólio acadêmico não quer previsibilidade de respostas, quer pessoalidade nas respostas. Foi enfocando esses aspectos da prática de escrita favorecidos pelo gênero portfólio acadêmico - i. organização/reelaboração; ii. reflexão; e iii. pessoalidade (autoria) - que a proposta de prática de escrita foi apresentada aos estudantes. E foi tendo em vista esses mesmos aspectos que os estudantes produziram seus textos, como veremos nas amostras a seguir. 
O produto dessa prática de escrita foram 14 textos, um para cada encontro/aula, ao longo dos quatro meses que compõem o semestre acadêmico. A seguir, apresento exemplos comentados dessas produções.

\section{Excerto 1 (Introdução)}

Quero mostrar como meu pensamento está crescendo e está sendo educado com esse portfólio. [...].

Eu ia para minha casa depois de aula, e assim que chegava, começava a escrever. Ou seja, esse portfólio é muito precioso para mim. Por isso, espero que você leia com interesse mesmo se eu não pude explicar bem o que eu queria falar.

No excerto 1, a estudante destaca o potencial do portfólio acadêmico para expandir o seu conhecimento e, ao mesmo tempo, favorecer a organização do seu pensamento. Ao afirmar que o portfólio "educa" a sua forma de pensar, a estudante aponta para um dos pontos fortes do trabalho com esse gênero no contexto acadêmico: o desenvolvimento da autonomia do estudante, que é levado a "(re)educar" a sua relação com a escrita, em particular, e com a aprendizagem, de modo amplo. Na sua introdução, a estudante revela que ela passa a reelaborar suas anotações de aula assim que chega em casa, indicando sua inserção em uma necessária etapa do processo de letramento escrito: a organização do pensamento e a reelaboração da informação nova, o que possibilita a geração de um texto crítico-reflexivo, ou seja, um texto em que o sujeito se posiciona frente ao tema abordado e se insere no seu texto, configurando-o como um texto autoral. Esses mesmos aspectos foram também destacados por outra estudante:

\section{Excerto 2 (Conclusão)}

Pessoalmente, o objetivo meu desse curso é comparar os aspectos do Brasil com os da Coreia, e saber quais são comuns e quais são diferentes.

Porém, como a Coreia e o Brasil não tinha muita relação historicamente, e porque a distância entre si é bem grande, não há pesquisas bastante sobre a relação dos dois países. Participando dessa aula, comecei a pensar que eu sou responsável por isso sendo estudante que estuda o Brasil na Coreia. O portfólio me deu o motivo para me interessar nessa área e continuar a estudar. Todos os temas que foram abordados aqui podem ser temas para pesquisas.

[...] Escrever o que aprendi ajudou-me a organizar meus pensamentos. Percebi que a capacidade de organizar bem o pensamento é a principal habilidade para se comunicar bem com os outros. Além disso, consegui conhecer o campo de estudos que me interessa preparando o portfólio. Vou poder continuar a estudar melhor baseado no que aprendi aqui. 
No excerto 2, a conclusão elaborada pela estudante mostra que a prática de escrita proposta favoreceu um importante aspecto da aprendizagem: o desejo de aprender mais, de investigar, de pesquisar, expandindo o processo de aprendizagem para além do que é possível ser construído dentro dos limites da sala de aula. Trata-se de um importante componente para o desenvolvimento da autonomia do estudante em relação à sua própria aprendizagem e formação acadêmica. Em um segundo momento, a estudante destaca o favorecimento da organização do pensamento propiciado pela prática proposta e ressalta, ainda, a importância desse procedimento para o desenvolvimento da habilidade de se comunicar bem, habilidade essencial para um bom desempenho comunicativo tanto em língua materna quanto em língua estrangeira. A estudante ainda frisa a etapa de reelaboração do conhecimento construído em sala no momento da escrita do portfólio, gênero com o qual ela ainda não havia travado contato:

Excerto 3 (Introdução)

Este portfólio acadêmico do Seminário sobre Sociedade e Cultura Brasileira será meu primeiro portfólio. Aqui, vou escrever minhas ideias sobre os aspectos culturais do Brasil e $\underline{0}$ que surgiu na minha mente quando estava aprendendo sobre eles.

Na produção textual de outra estudante, destacam-se três avaliações que ela faz do seu processo de escrita, desde o primeiro contato com esse gênero textual durante a apresentação da proposta pelo professor até a conclusão da prática e a entrega do portfólio:

\section{Excerto 4 (Introdução)}

Eu entrei nessa universidade para aprender uma coisa mais profunda, discutir temas mais polêmicos e ser uma pessoa melhor. Mas a realidade da universidade é totalmente diferente do que eu tinha esperança. Os professores, em geral, ensinam sem entusiasmo, não preparando para dar aulas. Mas tinha algumas aulas de boa qualidade, claro. Passando 3 anos com essas aulas, eu comecei a esquecer o que eu queria, acostumei com esse jeito de estudar e perdi até a vontade de aprender. Na verdade, eu escolhi a sua aula para obter o crédito para me formar. Por isso, eu estava procurando uma aula mais fácil, mas sua primeira aula, que é para nós sabermos como a aula vai correr foi bem difícil e fiquei chocada-especialmente os portfólios. Contudo, eu decidi a seguir a sua aula porque tinha esperança que sua aula poderia salvar meu entusiasmo desaparecido. E também sabia que poderia melhorar minha habilidade de expressão minha opinião em portuquês com mais lógica através do portfólio. 
[...] Me impressionou muito. Tenho uma visão nova pela sua aula e pelo trabalho do portfólio para ver a sociedade brasileira. Algumas coisas são parecidas com o Brasil, mas algumas coisas são totalmente diferente da Coreia.

[...] Agora eu aprendi como tenho que ver o mundo. Todos os países têm sua história e essa história afeta sua cultura.

A primeira avaliação feita pela estudante é de que o gênero portfólio lhe pareceu muito difícil, contrariando sua expectativa de uma "aula fácil". Essa avaliação reforça nossa observação de que os estudantes do nosso contexto universitário sul-coreano têm pouca familiaridade com o gênero portfólio, o que faz com que, em um primeiro momento, considerem práticas de escrita como a que foi proposta como "bem difíceis".

A segunda e a terceira avaliações dizem respeito à expectativa da estudante de melhorar a sua habilidade para se expressar em língua portuguesa e ao modo como ela passa a "ler" a sociedade e a cultura brasileira através da escrita do portfólio. Essa expectativa parece ter sido atendida e, juntamente com o desenvolvimento da habilidade escrita, a estudante indica que a aula, associada à prática de escrita do portfólio, possibilitou a ela ter "uma visão nova [...] para ver a sociedade brasileira".

Tomando-se a avaliação feita por essa última estudante, podemos considerar que a prática de escrita do portfólio favoreceu o seu posicionamento crítico em relação aos tópicos socioculturais tratados durante o semestre letivo, distanciando-se, portanto, dos "exercícios de copiação" e favorecendo a reflexão e o posicionamento crítico, ampliando a sua visão do tópico sociocultural trabalhado em sala de aula. Os estudantes passam a escrever a sociedade e a cultura brasileira a partir de informações trazidas pelo professor e de discussões em sala de aula, mas também a partir da sua própria inscrição nesses temas, comparando o Brasil e a Coreia e desconstruindo, nesse processo de escrita, estereótipos: "Algumas coisas são parecidas com o Brasil, mas algumas coisas são totalmente diferente da Coreia". Nem "paraíso" nem "inferno" na Terra. Muito diferente da Coreia e, ainda assim, bastante parecido em alguns aspectos. Um país como muitos outros e, simultaneamente, um país diferente de todos os outros.

Outro aspecto positivo do portfólio acadêmico ressaltado por outra estudante é a sua capacidade de proporcionar uma experiência de escrita que extrapola a sala de aula e se estende para outros espaços, dilatando-se para além dos 50 minutos da organização escolar:

\section{Excerto 5 (Conclusão)}

Durante 3 anos na minha faculdade, eu tinha muitas aulas de histórias e economia brasileira mas nunca tive aula de sociedade e cultura. Foi muito satisfatório porque podia pensar em problema e assuntos permanentes do Brasil. Mas, se a aula acabasse na sala, seria 
difícil organizar minhas opiniões e impressões de forma lógica. Escrever em língua estrangeira é certamente complicado mas pelo meu portfólio eu conseguia construir o meu próprio ponto de vista sobre o Brasil. [...] Era mesmo boa experiência para saber a cara destapada do Brasil.

Essa estudante também destaca a contribuição do portfólio acadêmico para a construção de um ponto de vista pessoal sobre o Brasil. Essa prática de escrita possibilitou uma reflexão sobre aspectos até então pouco investigados por ela sobre a sociedade e a cultura brasileira. A cada página do seu portfólio, a estudante foi capaz de desvelar mais um dos inúmeros véus que recobrem nossa sociedade, até alcançar o que ela considera "a cara destapada" do Brasil.

Para facultar aos estudantes meios de avançar nesse processo (infinito) de revelação da "cara destapada do Brasil", um dos tópicos do Seminário foi o conceito de "homem cordial" e a noção de "jeitinho brasileiro". O conceito foi pela primeira vez apresentado pelo historiador Sérgio Buarque de Holanda (1902-1982) em seu clássico Raízes do Brasil; já a noção foi discutida com os estudantes a partir de texto do jornalista Oscar Pilagallo. Esse tópico, já de saída complexo mesmo para um brasileiro, afigura-se ainda mais desafiador para um estudante coreano. Por isso, dois encontros foram dedicados ao tema, que foi, posteriormente, desenvolvido pelos estudantes em sua prática de escrita do portfólio. A análise de excertos de algumas dessas produções indica que o portfólio acadêmico pode ser particularmente apropriado para o trabalho com temas complexos, já que permite ao estudante um tempo de maturação e de reflexão, via escrita, sobre a discussão desenvolvida em sala. $O$ gênero portfólio acadêmico permitiu inclusive que os estudantes comparassem diferentes tópicos do Seminário, percebendo-os como inter-relacionados e não como informações segmentadas e sem conexão:

Excerto 6 (Brasil 2018-2022 - Panorama atual e expectativas)

Por que a sociedade brasileira tem tanta dificuldade para mudar? [Tópico: Brasil 20182022 - Panorama atual e expectativas] Todas as respostas podem ser encontradas nas aulas até agora. A característica de "homem cordial" [Tópico: Formação histórica da sociedade brasileira - O jeitinho do homem cordial"] fortaleceu as relações entre as classes dominantes, que fortaleceram o seu poder. De outro lado, o "colonialismo mental" [Tópico: "Colonialismo mental e nacionalismo ingênuo"] criou um sentimento de desamparo contra qualquer mudanças nas classes baixa. E a maneira mais fundamental de mudar isso é a educação [Tópico: Panorama setorial da cultura brasileira], mas todos sabem que a educação pública no Brasil não desempenhou o seu papel até agora". 
Conectando cada um desses quatro tópicos via escrita do portfólio, a estudante foi capaz de estabelecer relações mais complexas em relação à sociedade brasileira atual, procurando lê-la e compreendê-la a partir de suas raízes coloniais, de sua formação histórica e de suas lutas de classe.

O tópico "Relações étnico-raciais no Brasil" foi um dos que mais surpreendeu os estudantes - e um dos que mais os engajou em sua prática de escrita do portfólio. Tendo nascido em uma sociedade que sempre considerou a sua (mítica) "pureza racial" como um valor a ser resguardado, os estudantes coreanos têm as suas próprias experiências com o racismo. Ser "não coreano" na Coreia do Sul é suficiente para você ser olhado e avaliado como "estranho", assim como ter a cor da pele menos clara, mesmo entre coreanos, é suficiente para você ser considerado como um indivíduo low class e, por isso, ser menos respeitado. Mesmo sabendo que o racismo não é um problema exclusivamente brasileiro, o impacto social do racismo no Brasil surpreende e choca os estudantes coreanos:

Excerto 7 (Relações étnico-raciais no Brasil)

Choquei. Choquei muito quando eu ouvi a música "Carne"6 pela primeira vez. Claro que eu não conseguia entender toda a letra. Mas a frase "A carne mais barata do mercado é a carne negra" é bem chocante. O significado por dentro dessa frase é muito profundo. Ainda hoje, dentro do Brasil ou fora do Brasil, tem bastante discriminação racial invisível. No meu pensamento, a maneira mais poderosa desse racismo invisível é a discriminação econômica de que eu falei na semana passada".

Em seu portfólio acadêmico, a estudante demonstra sua habilidade de relacionar a letra da música ao tema discutido em sala de aula, ao mesmo tempo em que assinala o seu ponto de vista sobre as relações étnico-raciais no Brasil. A frase que ela destaca da canção é "bem chocante", mas a estudante avança em sua análise do tema-canção e busca depreender o significado que há "por dentro dessa frase". Em sua escrita, ela arrisca uma hipótese para esse "significado profundo", relacionando a dimensão invisível do racismo (no Brasil e no mundo) e a discriminação econômica, relação essa que, no Brasil, conhecemos tão bem, mas que pode não ser prontamente estabelecida pelos estudantes coreanos, inseridos que estão em uma realidade social bem diversa da nossa: "Um trabalhador negro chega a receber $50,7 \%$ do salário de um branco, ambos desenvolvendo a mesma atividade", segundo o IBGE e o IPEA7.

\footnotetext{
${ }^{6}$ Canção "A carne", gravada por Elza Soares, cujo refrão é "A carne mais barata do mercado é a carne negra". Disponível em: https://www.youtube.com/watch?v=yktrUMoc1Xw. Acesso em: 12 jun. 2018. ${ }^{7}$ Disponível em: http://www.innovarepesquisa.com.br/blog/infografico-o-reflexo-racismo-brasil/. Acesso em: 12 out. 2018.
} 
No portfólio de outra estudante, pode-se ler as seguintes considerações sobre esse mesmo tópico:

Excerto 8 (Relações étnico-raciais no Brasil)

Sob o slogan de um país multiétnico e multicultural, as pessoas que não vivem no Brasil acreditam que não há discriminação racial no Brasil. Mas isso é totalmente mentira. Na história do Brasil, os negros vieram para o Brasil pela primeira vez como escravos. As classes, separadas desde o início, ainda não desapareceram da sociedade brasileira. Isso mostra que, depois do comércio de escravos negros foi banido e a escravidão abolida, faltam esforços para eliminar o racismo. Aliás, não há quase mudança na hierarquia da sociedade moderna em comparação com aqueles dias. [...]

Felizmente, a porcentagem de estudantes negros que ingressam nas universidades nos últimos anos vem aumentando e há pessoas notáveis lutando contra o racismo. O que a sociedade brasileira deveria fazer agora é ter uma voz mais forte com esses líderes negros.

Através da escrita do seu portfólio, a estudante avança para além da imagem estereotipada de um Brasil como país em que todas as raças convivem harmoniosamente "sob o slogan de um país multiétnico e multicultural", desconstruindo o mito da democracia racial no qual a sociedade brasileira se apoiou. A estudante avalia a questão étnico-racial do ponto de vista histórico, refletindo sobre as consequências do tráfico negreiro e analisando, na sociedade brasileira contemporânea, os impactos das políticas de ações afirmativas que possibilitaram o ingresso inédito de estudantes negros em larga escala nas universidades brasileiras. Sua escrita da sociedade e da cultura brasileira é visivelmente crítica e fortemente autoral, características essas possibilitadas pelo modo como as relações de poder e as identidades estudante-autor/professor-leitor foram construídas e incentivadas ao longo das etapas que envolveram a confecção do portfólio acadêmico, prática de escrita que colocou os estudantes em uma posição de autonomia/autoria para se inscreverem nos seus próprios textos.

\section{Considerações finais}

Apesar da pouca familiaridade dos estudantes coreanos com o gênero portfólio, a adoção de uma perspectiva ideológica de letramento acadêmico possibilitou engajá-los nessa prática de escrita através da adaptação desse gênero textual ao contexto pedagógico específico e da construção de identidades discursivas que estimularam a autonomia dos estudantes de Estudos Brasileiros em seu envolvimento com o texto escrito. A prática proposta aos estudantes coreanos proporcionou, assim, condições para uma importante 
mudança de perspectiva em relação ao processo de escrita: alterando o modo como os estudantes se relacionavam com o texto, foi possível promover o deslocamento de uma visão de escrita como "reprodução de informações trazidas pelo professor ou copiadas de outros textos" para uma perspectiva de escrita como "processo em que os sujeitos interagem através da linguagem [e] nessas interações, os sujeitos compreendem, concordam, discordam, interrogam seus interlocutores" (GLOSSÁRIO CEALE). Na prática realizada, o gênero portfólio acadêmico saiu de um lugar inicial pouco ou nada familiar ao estudante coreano para se transformar, gradativamente, nesse espaço discursivo no qual o estudante descobriu como se fazer autor do seu próprio texto: concordando, discordando e, principalmente, interrogandose, interrogando a sua cultura, a cultura do outro e as diferentes representações que se sedimentam sobre ambas.

A análise das amostras de textos produzidos pelos estudantes indica que a prática de escrita baseada no gênero portfólio acadêmico pode favorecer a autonomia no processo de aprendizagem e estimular a construção da autoria na escrita, sendo essa prática bem-vinda no contexto universitário sul-coreano, o qual parece nem sempre oportunizar aos seus estudantes o engajamento em práticas variadas de escrita acadêmica conduzidas sob o modelo ideológico de letramento.

\section{Referências}

AMBRÓSIO, Márcia. O uso do portfólio no ensino superior. Petrópolis, RJ: Vozes, 2013.

BAKHTIN, Mikhail. Os gêneros do discurso. In: BAKHTIN, Mikhail. Estética da criação verbal. Trad. Paulo Bezerra. 6. ed. São Paulo: Editora WMF Martins Fontes, 2011. p. 261-306.

FIAD, Raquel Salek. A escrita na universidade. Revista da ABRALIN, v. Eletrônico, n. Especial, 2011, p.357-369. 2a parte. https://doi.org/10.5380/rabl.v10i4.32436

FIAD, Raquel Salek. Reescrita, dialogismo e etnografia. Linguagem em (Dis)curso, Tubarão, SC, v. 13, n. 3, 2013, p.463-4. https://doi.org/10.1590/S1518-76322013000300002

FRANCISCO, D. L. Aulas com interação: ensinando (e aprendendo) língua portuguesa e cultura brasileira na Coreia do Sul. Rev. EntreLínguas, Araraquara, v.4, n.1, p. 133-142, jan./jun., 2018. https://doi.org/10.29051/rel.v4.n1.2018.11179

HENDERSON, Robyn; HIRST, Elizabeth. Reframing academic literacy: reexamining a short course for "disadvantaged" tertiary students. English teaching: practice and critique. v. 2, n. 6, 2007, p. 25-38. Disponível em: https://files.eric.ed.gov/fulltext/EJ832186.pdf. Acesso em: 14 jun. 2018.

HOLANDA, Sérgio Buarque de. Raízes do Brasil. 26. ed. São Paulo: Companhia das Letras, 1995 [1936].

$\mathrm{KOCH}$, Ingedore; ELIAS, Vanda Maria. Ler e compreender os sentidos do texto. São Paulo: Contexto, 2018 [2006]. 
$\mathrm{KOCH}$, Ingedore; ELIAS, Vanda Maria. Ler e escrever: estratégias de produção textual. São Paulo: Contexto, 2018 [2009].

LEA, M. R.; STREET, B.V. Student writing in higher education: an academic literacies approach. Studies in Higher Education, v. 23, 1998, p. 157-172. https://doi.org/10.1080/03075079812331380364

MARCUSCHI, Luiz Antônio. Exercícios de compreensão ou copiação nos manuais de ensino de língua? In: Revista em Aberto. Brasília: INEP-MEC, 1996.

MARCUSCHI, Luiz Antônio. Gêneros textuais: definição e funcionalidade. In: DIONISIO, Angela Paiva; MACHADO, Anna Rachel; BEZERRA, Maria Auxiliadora. (Orgs.). Gêneros textuais e ensino. São Paulo: Parábola Editorial, 2010. p.19-38.

MARINHO, Marildes. A escrita nas práticas de letramento acadêmico. RBLA, Belo Horizonte, v. 10, n. 2, 2010, p.363-386. https://doi.org/10.1590/S1984-63982010000200005

MOTTA-ROTH, Désirée. The role of context in academic text production and writing pedagogy. In: Bazerman, C.; Bonini, A; Figueiredo, D. (Eds). Genre in a changing world. Colorado: The WAC Clearinghouse, 2009. Ch 16, p.317-336.

MOTTA-ROTH, Désirée; HENDGES, Graciela Rabuske. Produção textual na universidade. São Paulo: Parábola Editorial, 2010.

PILAGALLO, Oscar. $O$ jeitinho do homem cordial. Disponível em: http://www2.uol.com.br/historiaviva/reportagens/o jeitinho do homem cordial.html.

Acesso em: 06 mar. 2017.

PRODUÇÃO DE TEXTO. In: GLOSSÁRIO Ceale. Disponível em: http://ceale.fae.ufmg.br/app/webroot/glossarioceale/verbetes/producao-de-textos. Acesso em: 12 set. 2018.

SELDIN, P. The teaching portfolio: a practical guide to improved performance and promotion/tenure decisions. Boston: Anker Publishing, 2004.

STREET, B. V. Abordagens alternativas ao letramento e desenvolvimento. Artigo apresentado durante a Teleconferência UNESCO Brasil sobre letramento e diversidade, 2003.

STREET, B. V. Letramentos sociais. São Paulo: Parábola, 2014.

STREET, B. V. Literacy in theory and practice. Cambridge: Cambridge University Press, 1984.

STREET, B. V. Os novos estudos do letramento: histórico e perspectivas. In: MARINHO, M.; CARVALHO, G. T. (Org.). Cultura escrita e letramento. Belo Horizonte: Editora UFMG, 2010. p. 33-53

STREET, B. V. Social literacies: critical approaches to literacy in development, ethnography and education. London and New York: Longman, 1995.

Recebido em: 31/01/2019

Aceito em: 02/06/2019 